\title{
Detection of chromosomal imbalances in children with idiopathic mental retardation by array based comparative genomic hybridisation (array-CGH)
}

\author{
J Schoumans, C Ruivenkamp, E Holmberg, M Kyllerman, B-M Anderlid, M Nordenskjöld
}

Chromosomal aberrations are a common cause of multiple anomaly syndromes that include growth and developmental delay and dysmorphism. Novel high resolution, whole genome technologies, such as array based comparative genomic hybridisation (array-CGH), improve the detection rate of submicroscopic chromosomal abnormalities allowing re-investigation of cases where conventional cytogenetic techniques, Spectral karyotyping (SKY), and FISH failed to detect abnormalities. We performed a high resolution genome-wide screening for submicroscopic chromosomal rearrangements using array-CGH on 41 children with idiopathic mental retardation (MR) and dysmorphic features. The commercially available microarray from Spectral Genomics contained 2600 BAC clones spaced at approximately $1 \mathrm{Mb}$ intervals across the genome. Standard chromosome analysis ( $>450$ bands per haploid genome) revealed no chromosomal rearrangements. In addition, multi-subtelomeric FISH screening in 30 cases and SKY in 11 patients did not detect any abnormality. Using array-CGH we detected chromosomal imbalances in four patients $(9.8 \%)$ ranging in size from 2 to $14 \mathrm{Mb}$. Large scale copy number variations were frequently observed. Array-CGH has become an important tool for the detection of chromosome aberrations and has the potential to identify genes involved in developmental delay and dysmorphism. Moreover, the detection of genomic imbalances of clinical significance will increase knowledge of the human genome by performing genotypephenotype correlation.

$\mathrm{S}$ egmental aneusomy is a common cause of malformations and mental retardation (MR). Rearrangements involving large chromosomal segments can be detected by standard chromosome analysis using GTG-banding, but this technique is not suited for the detection of small chromosome abnormalities. Subtelomeric abnormalities are found in about $5 \%$ of mentally retarded patients ${ }^{12}$ when investigated by subtelomeric screening methods. However, these methods only reveal chromosome rearrangements located in the subtelomeric regions, and the relatively frequent observation of subtelomeric aberrations implies that small interstitial gene dose alterations may be as common but are overlooked. High resolution comparative genomic hybridisation (HR-CGH) performed on metaphase chromosomes has been used for genome-wide screening for chromosomal imbalances in patients with idiopathic MR. ${ }^{3}$ However, the resolution of CGH performed on metaphase chromosomes is limited and most likely depends on the structure and condensation of certain chromosome regions. ${ }^{5}$
On the other hand, when performing CGH on DNA clones immobilised on a glass surface (array based CGH), ${ }^{6}$ the resolution is determined by the size of the clones and the genomic distance between the clones. Array-CGH is a powerful tool for detecting very small chromosomal imbalances. This approach has revealed submicroscopic chromosome aberrations in patients with idiopathic MR with detection rates as high as $15-24 \% .^{78}$ These findings prompted us to study children with idiopathic MR and dysmorphic features, in whom G-banding karyotypes were normal. In addition, subtelomeric screening had been performed in the majority of the cases (30/41) and a small number of these cases (11) had also been investigated by Spectral karyotyping (SKY), without revealing any abnormalities. Using array based comparative genomic hybridisation (array-CGH) with a resolution of approximately $\mathrm{l} \mathrm{Mb}$, in a set of $4 \mathrm{l}$ cases we found aberrations in four. All cases had a de novo interstitial deletion. In addition to probable causative chromosome imbalances, we detected large copy number variants (LCVs) using array-CGH. The frequent occurrences of large size copy number polymorphisms in the human genome have recently been reported. ${ }^{9} 10$

\section{METHODS}

\section{Patient selection}

A total of 41 patients ( 22 girls and 19 boys between 6 months and 16 years old) with a phenotype highly suggestive of a disorder of chromosomal origin were selected. The phenotype included dysmorphic features, malformations, and/or a family history in combination with mild to severe MR. The selected patients scored at least 3 points on the checklist developed by de Vries et al. ${ }^{11}$ All 41 patients had been analysed by standard G-band analysis ( $>450$ band resolution), 30 of the patients had been screened for subtelomeric aberrations by FISH, and 11 cases had also been investigated by SKY. ${ }^{12}$ Normal karyotypes had been found in all patients.

\section{Array-CGH}

Genomic DNA was extracted from peripheral venous blood samples, EBV transformed lymphocytes, or cultured fibroblasts using a Puregene blood kit (Gentra Systems, Minneapolis, MN) according to the manufacturer's protocol. Genomic DNA from the patients was digested into fragments of 100-2000 bp by overnight incubation at $37^{\circ} \mathrm{C}$ with $D p n$ II (New England Biolabs, Beverly, MA) at $37^{\circ} \mathrm{C}$ and checked on a $2 \%$ agarose gel. The DNA fragments were purified using a Qiaquick PCR purification kit (Qiagen, Hilden, Germany).

Abbreviations: array- $\mathrm{CGH}$, array based comparative genomic hybridisation; $\mathrm{HR}-\mathrm{CGH}$, high resolution comparative genomic hybridisation; LCVs, large copy number variants; MR, mental retardation; SKY, Spectral karyotyping; WHS, Wolf Hirshhorn syndrome 
Array-CGH was performed using arrays containing 2600 BAC clones (Spectral Genomics, Houston, TX) as previously described, ${ }^{13}$ with some minor modifications. Briefly, $1 \mu \mathrm{g}$ of digested genomic DNA was labelled with Cy5-dCTP or with Cy3 dCTP (Amersham Biosciences, Buckinghamshire, UK) using random prime labelling (Bioprime Labeling Kit, Invitrogen, Carlsbad, CA). Labelled test and reference DNA were mixed and unincorporated nucleotides were removed using a Qiaquick PCR purification kit (Qiagen, Hilden, Germany) prior to co-precipitation with Spectral hybridisation buffer I. The DNA pellet was re-suspended in Spectral hybridisation buffer II (Spectral Genomics). After denaturation, the probe was applied on the array and overnight hybridised at $37^{\circ} \mathrm{C}$ in a hybridisation chamber (Corning, Corning, NY). Slides were washed for $20 \mathrm{~min}$ each at $50^{\circ} \mathrm{C}$ in $50 \%$ formamid $/ 2 \times$ SSC, $2 \times$ SSC $/ 0.1 \%$ Tween 20 and $10 \mathrm{~min}$ in $0.2 \times$ SSC and immediately nitrogen blow dried. Colour reverse experiments were performed and, to minimise the costs, each investigated case was hybridised once against reference DNA consisting of a pool of 10 normal individuals (Promega, Mannheim, Germany) and once against another patient with a different clinical phenotype.

\section{Array data analysis}

Arrays were scanned in a fluorescence confocal scanner (Scan Array Lite, GSI Lumonics, Billerica, CA) and images were analysed using GenePix Pro 3.0 software (Axon Instruments, Burlingame, CA). Spots were defined by the automatic grid feature of the software and manually adjusted when necessary. Spots showing no signal or obvious defects were excluded from the data analysis, local background was subtracted, and total intensities, as well as the fluorescence intensity ratios of the two dyes, were calculated for each spot. Further data analysis was performed using the online accessible version of SpectralWare software (Spectral Genomics) using global mean normalisation of the data. In addition, the datasets were analysed using Microsoft Excel. After performing global mean and global median normalisations, the mean ratios of four fluorescent signals (two signals from the duplicated clone on the array and two signals from the colour reverse experiment) for each clone were calculated. All analysis was done on $\log _{2}$ ratios. To reduce false positive results, clones showing test/reference ratio value higher than 1.2 were considered gained and clones showing test/reference ratio value lower than 0.8 were considered lost, but only if the results of all four fluorescent signals were consistent. Clones were excluded from analysis if the ratio values of the four hybridised spots of each clone exceeded the threshold values $(0.8-1.2)$ in a non-concordant matter.

\section{FISH confirmation of array analysis}

BAC clones spotted on the array showing gains or losses were subjected to FISH confirmation. All clones were obtained from The Welcome Trust Sanger Institute (Cambridge, UK) or BACPAC Resource Center Children's Hospital (Oakland Research Institute, Oakland, CA). Bacterial cultures and DNA isolation were performed according to the BAC-PAC miniprep protocol from the Resources for Molecular Cytogenetics, University of Bari website (http://www.biologia.uniba.it/ rmc). Probes were labelled with FITC-dUTP (NEN Life Science Products, Boston, MA) or SpectrumOrange-dUTP (Vysis, Downers Grove, IL) by nick translation, and FISH analyses were performed according to a standard protocol on metaphase slides that were prepared from lymphocyte cultures of peripheral blood or from fibroblast cultures. The slides were analysed on a Zeiss Axioplan 2 (Carl Zeiss, Göttingen, Germany) epifluorescence microscope and images were captured using a cooled CCD camera (Sensys
Photometrics, München, Germany) and SmartCapture 2 software (DigitalScientific, Cambridge, UK). FISH signals were examined both on metaphase chromosomes and interphase nuclei. Control probes and inverted DAPI staining were used for chromosome identification.

\section{RESULTS}

We screened 41 mentally retarded children with dysmorphic features, for submicroscopic chromosomal imbalances by array-CGH. All patients had an apparently normal balanced karyotype when investigated by standard G-banding ( $>450$ band resolution). In addition, multi-subtelomeric FISH was performed on the majority of the patients ( 30 out of 41 ) and 11 cases were investigated by SKY without revealing any rearrangements. ${ }^{12}$ We detected four de novo interstitial deletions. The results are summarised in table 1. A large number of single clone gains and losses interpreted as normal variants are listed in table 2. All four de novo aberrations were confirmed by metaphase FISH and parental samples were investigated by metaphase FISH and G-banding. Metaphase FISH investigation on the parental samples was performed using three to six differentially labelled clones, located in or flanking the region of interest, in order to exclude inversions.

For verification of single clone variants, metaphase- and interphase-FISH was used. However, as expected, these relatively small microduplications and microdeletions proved to be difficult to validate by conventional FISH since the breakpoints of the duplications or deletions might be within the clone and only variable FISH signal intensity could be observed. Parental samples were not available in the majority of the cases to investigate parental inheritance of the polymorphisms. We interpreted aberrant signals from single clones as polymorphisms if they were detected in two or more unrelated patients not sharing the same phenotype or if the clones were listed in the online publicly accessible Database of Genomic Variants (http://projects.tcag.ca/variation). All but two of the polymorphic clones (RP11-130P22 and RP1157D6, table 2) were already listed in the database. ${ }^{910}$

\section{Case 1}

Case 1 was a 2 year old girl with severe MR, dysmorphic facial features (synophrys, long eyelashes, depressed nasal bridge, long philtrum, crescent shape mouth), prenatal growth deficiency, severe epilepsy, cleft palate, hirsutism, camptodactyly, and syndactyly. A deletion spanning 12 clones with an estimated size of $10 \mathrm{Mb}$ was identified, located on chromosome band 2q24-31. The deletion is probably the cause of the girl's phenotype, since her clinical features overlap greatly with those mentioned in previous reports..$^{14}$ In retrospect, a subtle deletion could be revealed by re-investigation of G-band analysis (fig lA).

\section{Case 2}

Case 2 was a 13 year old girl with severe MR, microcephaly, anal atresia, heart malformations (VSD, PDA, and hypoplastic aortic arch), postnatal growth retardation, susceptibility to infections, and facial dysmorphism (synophrys, long eyelashes, low set prominent ears, down turned corners of the mouth). A deletion of approximately $14 \mathrm{Mb}$, involving 13 BAC clones located in chromosome band 2q22.3-24.1, was identified by array-CGH. The deletion was confirmed by metaphase FISH (fig lb). Because of the relatively large size of the deletion revealed by array-CGH, G-band karyotype was re-investigated and revealed a very subtle deletion (fig 1B). This de novo deletion is most likely the underlying cause of the girl's phenotype, which had some overlap with a previously reported case with $\operatorname{del}(2 \mathrm{q})(\mathrm{q} 22.3 \mathrm{q} 23.3) .{ }^{16}$ The ZFHXIB (SIPI) gene, associated with Mowat-Wilson 
Table 1 Phenotypes and detected chromosome imbalance

\begin{tabular}{|c|c|c|c|c|c|c|c|c|c|}
\hline Case & Gender & Age & MR & Phenotype & $\begin{array}{l}\text { Chromosome } \\
\text { imbalance }\end{array}$ & $\begin{array}{l}\text { Estimated } \\
\text { size in } \\
\mathrm{Mb}\end{array}$ & Array-CGH results & Origin & Deleted clones \\
\hline 1 & Female & 2 & Severe & $\begin{array}{l}\text { Facial dysmorphism, } \\
\text { seizures, cleft palate, } \\
\text { hirsutism, prenatal } \\
\text { growth retardation, } \\
\text { syndactyly, and } \\
\text { camptodactyly }\end{array}$ & $\operatorname{del}(2)(q 24.3 q 31.1)$ & 10 & Deletion of 12 clones & De novo & $\begin{array}{l}\text { RP11-91010, AC016723.11, } \\
\text { RP11-79E23, RP11-80D14, } \\
\text { RP11-81F17, RP11-91L3, RP11- } \\
\text { 79D11, RP11-911 23, RP11- } \\
91 A 9, \text { RP1 1.79C17, } \\
\text { AC013467.8, RP11-12N7 }\end{array}$ \\
\hline 2 & Female & 13 & Severe & $\begin{array}{l}\text { Facial dysmorphism, } \\
\text { seizures, microcephaly, } \\
\text { anal atresia, heart } \\
\text { malformations, } \\
\text { postnatal growth } \\
\text { retardation }\end{array}$ & $\operatorname{del}(2)(q 22.3 q 24.1)$ & 14 & Deletion of 13 clones & De novo & $\begin{array}{l}\text { RP1 1-357J9, RP1 167J2, RP11- } \\
\text { 90K5, AC018465.8, RP11- } \\
375 \mathrm{H} 16, \mathrm{RP} 11-79 \mathrm{~A} 11 \text {, RP1 1- } \\
\text { 364H22, RP11-185M22, RP1 1- } \\
\text { 17E6, RP11-11 1C17, RP1 1-44N6, } \\
\text { RP11-79B5, RP11-546J1 }\end{array}$ \\
\hline 3 & Female & 11 & Severe & $\begin{array}{l}\text { Facial dysmorphism, } \\
\text { pre- and postnatal } \\
\text { growth retardation, } \\
\text { microcephaly, seizures }\end{array}$ & $\operatorname{del}(4)(p 16.2 p 16.3)$ & 6 & Deletion of 11 clones & De novo & $\begin{array}{l}\text { RP1 1-262P20(E), RP1 1-262P20, } \\
\text { RP1 1-478C1, RP1 1-808B21, } \\
\text { RP3-323A24, RP1 1-520M5, } \\
\text { RP1 1-357G3, RP1 1-91B20, } \\
\text { RP1 1-89K12, AC092463.5, } \\
\text { RP1 1-101J14 }\end{array}$ \\
\hline 4 & Male & 10 & $\begin{array}{l}\text { Mod- } \\
\text { erate }\end{array}$ & $\begin{array}{l}\text { Facial dysmorphism, } \\
\text { postnatal growth } \\
\text { retardation, overweight, } \\
\text { behavioural disorder, } \\
\text { sleeping disturbance }\end{array}$ & $\operatorname{del}(17)(p 11.2)$ & 2 & Deletion of 2 clones & De novo & RP11-90G21, RP11-404D6 \\
\hline
\end{tabular}

Table 2 Single clone normal variant detected by array-CGH

\begin{tabular}{|c|c|c|c|c|c|}
\hline Chromosome no. & Clone & Mb position & Cytoband & Gain & Loss \\
\hline \multirow[t]{5}{*}{1} & RP1-163M9 & 16.4 & $1 p 36.13$ & & 1 \\
\hline & RP6-65F20 & 57.3 & lp 32.2 & 1 & \\
\hline & RP4-601K24 & 82.9 & $1 \mathrm{p} 31.1$ & & 1 \\
\hline & RP11-259N12 & 103.5 & $1 \mathrm{p} 21.1$ & 8 & 8 \\
\hline & RP1 1-438F14 & 245.6 & lq44 & 1 & \\
\hline \multirow[t]{4}{*}{2} & RP11-130P22* & 46.5 & $2 \mathrm{p} 21$ & 2 & 3 \\
\hline & RP11-89B17 & 132.5 & $2 q 21.1$ & 1 & \\
\hline & RP11-31604 & 220.4 & $2 q 35$ & 4 & 2 \\
\hline & RP5-1011017 & 243.9 & $2 q 37.3$ & 1 & 1 \\
\hline 3 & RP11-57D6* & 13.2 & $3 p 25$ & 8 & 6 \\
\hline 4 & RPI-81N11 & 34.7 & $4 p 15.1$ & 1 & 4 \\
\hline \multirow[t]{3}{*}{5} & RP11-88L18 & 17.5 & $5 p 15.1$ & 2 & \\
\hline & RP11-19F13 & 41.2 & $5 p 13.1$ & & 1 \\
\hline & RP1 1-551B22 & 69.6 & $5 q 13.2$ & & 1 \\
\hline \multirow[t]{7}{*}{6} & AL035696.14 & 0.1 & $6 p 25.3$ & 1 & 1 \\
\hline & RP3-416J7 & 0.1 & 6p25.3 & 2 & 1 \\
\hline & RP1-209A6 & 23.1 & 6р22.3 & & 1 \\
\hline & RP1-271N20 & 62.2 & 6 centromer & 2 & \\
\hline & RP3-442I2 & 65 & $6 q 12$ & 1 & \\
\hline & RP11-80L16 & 67.1 & $6 q 12$ & 5 & 3 \\
\hline & RP1-104A17 & 71.5 & $6 q 13$ & 1 & \\
\hline \multirow[t]{3}{*}{7} & IIIB3 & 18.9 & $7 \mathrm{p} 21.1$ & 1 & \\
\hline & IID9 & 18.9 & $7 p 21.1$ & 1 & \\
\hline & AC004853.1 & 143 & $7 q 35$ & 1 & \\
\hline \multirow[t]{3}{*}{8} & RP11-1K11 & 4.6 & $8 p 23.2$ & & 1 \\
\hline & RP11-96G1 & 86.7 & $8 q 21.2$ & 1 & \\
\hline & RP1 1-449D3 & 137.7 & $8 q 24.23$ & & 2 \\
\hline 9 & RP11-9H12 & 111.2 & $9 q 32$ & & 1 \\
\hline \multirow[t]{2}{*}{10} & RP11-108K14 & 135.2 & $10 \mathrm{q} 26.3$ & & 3 \\
\hline & CTC-261B16 & 135.2 & $10 \mathrm{q} 26.3$ & & 3 \\
\hline \multirow[t]{2}{*}{13} & RP11-26D3 & 20.3 & $13 q 12.11$ & 5 & 2 \\
\hline & RP11-100D24 & 55.6 & $13 q 21.1$ & 10 & 1 \\
\hline 14 & RP11-125A5 & 27.5 & $14 q 12$ & 13 & 6 \\
\hline 15 & RP1-124O5 & 99.9 & $15 q 26.3$ & & 1 \\
\hline \multirow[t]{2}{*}{16} & RP1 1-488I20 & 35.5 & $16 p 11.2$ & 3 & \\
\hline & RP11-80F22 & 35.7 & $16 p 11.2$ & 4 & 1 \\
\hline \multirow[t]{2}{*}{17} & RP11-79018 & 45.2 & $17 q 21.31$ & 1 & \\
\hline & RP11-300G13 & 68.6 & $17 q 24.3$ & 1 & \\
\hline 18 & $\mathrm{Pl}-52 \mathrm{Mll}$ & 0.2 & $18 p 11.32$ & 1 & \\
\hline 19 & RP11-79F15 & 8.7 & $19 p 13.2$ & 4 & 7 \\
\hline \multirow{3}{*}{$x$} & RP6-64P1 4 & 120.7 & $\mathrm{Xq} 25$ & 1 & \\
\hline & $\mathrm{CH} 3.1$ & 152.1 & Xq28 & 1 & \\
\hline & & & Total & 89 & 62 \\
\hline
\end{tabular}


A
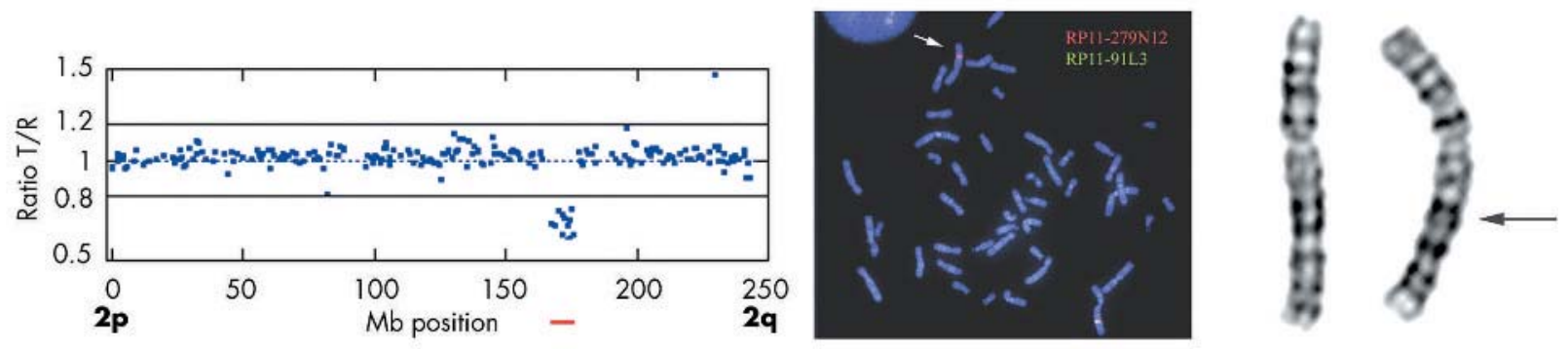

B
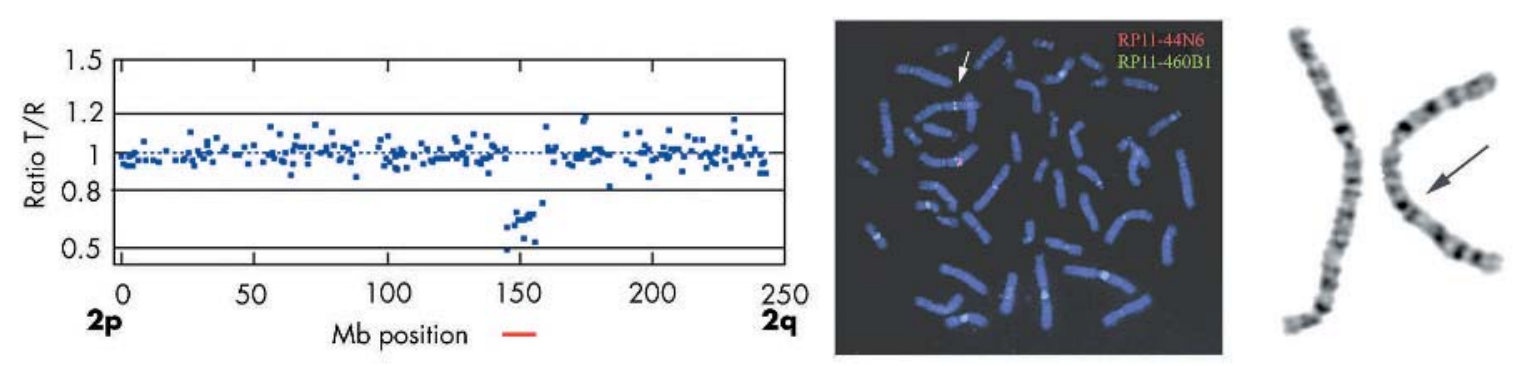

C
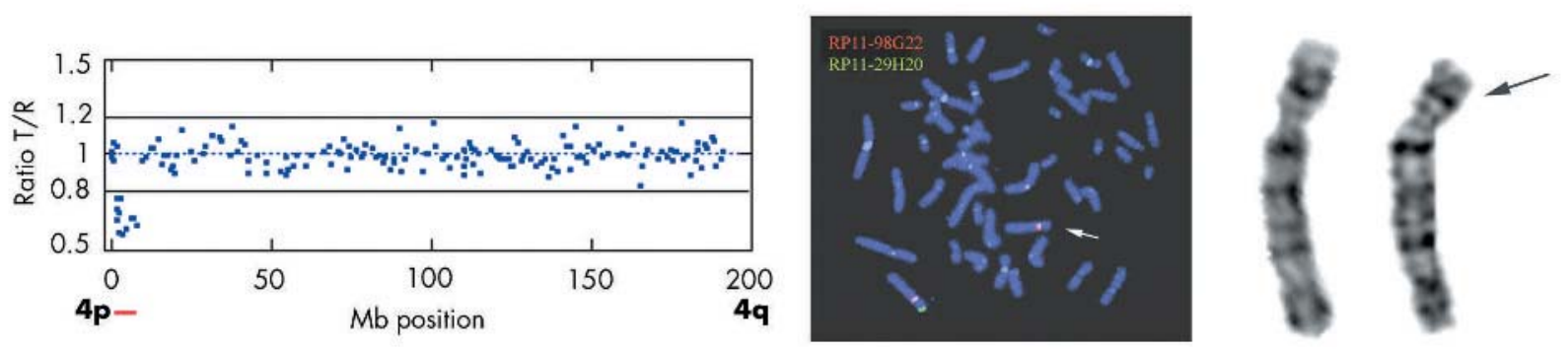

D
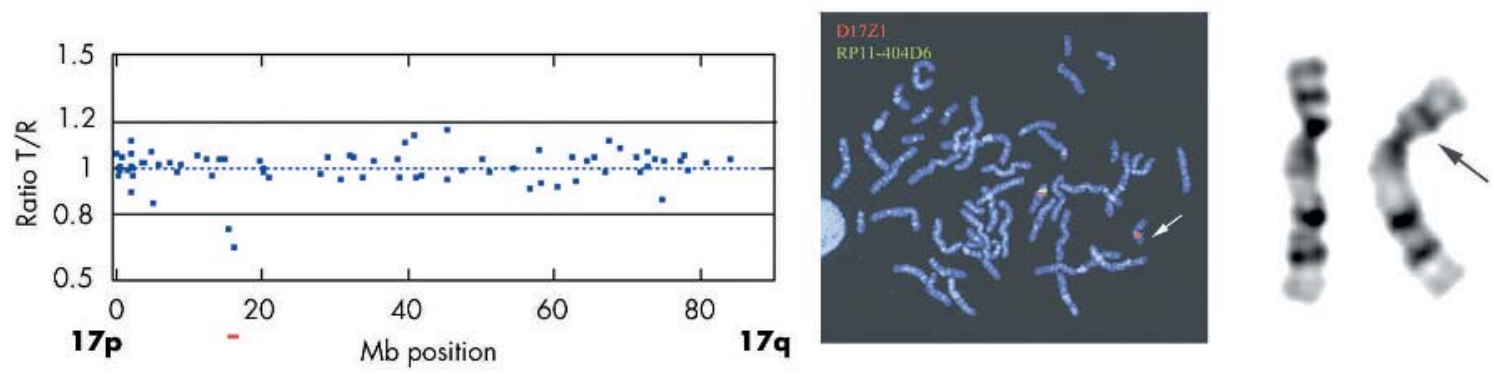

Figure 1 Array-CGH, FISH, and G-band images. Images on left: Array-CGH test/reference ratio plot of chromosomes displaying chromosomal aberration. The BAC clones are sorted according to their $\mathrm{Mb}$ genomic location along the chromosomes with the short arm (p) on the left and the long arm (q) on the right. Images in middle: Metaphase FISH confirmation using BAC clones showing aberrant ratios in the array analysis together with a chromosome specific control probe. Images on right: Giemsa stained chromosomes. (A) Case 1, chromosome 2: Array-CGH ratio plot from chromosome 2 displaying an interstitial deletion of 10 clones in cytogenetic band 2q24-3-q31. 1. A polymorphism is visible at clone RP1 1-316014 located at $\mathrm{Mb}$ position 220 showing a duplication (ratio close to 1.5). Metaphase FISH confirmation using BAC clone RP1 1-91L3 labelled with green located in the deletion and control probe RP1 1-279N1 2 labelled in red. A green signal on one 2q is missing indicating a deletion. Retrospective G-band analysis showing a subtle deletion on 2q. (B) Case 2, chromosome 2: Array-CGH ratio plot from chromosome 2 displaying an interstitial deletion of 14 clones in cytogenetic band 2q22-3-q24.1. Metaphase FISH confirmation using BAC clone RP1 1-44N6 labelled with red located in the deletion and control probe RP1 1-460B1 labelled in green. A red signal on one $2 q$ is missing indicating a deletion. Retrospective $\mathrm{G}$-band analysis showing a subtle deletion on 2q. (C) Case 4, chromosome 4: Array-CGH ratio plot from chromosome 4 displaying an interstitial deletion of 11 clones in cytogenetic band 4p16. Metaphase FISH confirmation using BAC clone RP1 1-29H20 labelled with green located in the deletion and control probe RP1 1-98G22 labelled in red presenting only one green signal on the deleted chromosome 4. Giemsa stained chromosomes showing a deletion on 4p. (D) Case 5, chromosome 17: Array-CGH ratio plot from chromosome 17 displaying an interstitial deletion of two clones in cytogenetic band 17p 1 1.2. Metaphase FISH confirmation using BAC clone RP1 1-404D6 labelled with green located in the deletion and a centromeric probe D17Z1 labelled in red showing only one green signal on the deleted chromosome 17. Giemsa stained chromosomes showing no deletion on 17p.

syndrome, ${ }^{17}$ is located close to the deletion in case 2. Therefore, FISH with a clone covering the ZFHXIB (SIPI) gene (RP11-107E5) was performed with normal results, indicating no deletion of this gene.

\section{Case 3}

In case 3, an 11 year old girl with severe MR, pre- and postnatal growth retardation, microcephaly, seizures, and facial dysmorphism (hypertelorism, epicantus, triangular 
face, and brachycephaly), we detected an interstitial deletion spanning 11 clones on 4 pl6.2-16.3, size estimated to be $6 \mathrm{Mb}$ (fig 1D). The deletion spans both the WHSCl and WHSC2 genes, associated with Wolf Hirshhorn syndrome (WHS). In retrospect the classical characteristic facial features of this syndrome were recognised in the girl. We mapped the proximal breakpoint of the deletion by FISH using clone RPl1-1197E19, covering the LETMl gene. Deletions causing haplo-insufficiency for LETM1 (a calcium channel gene located at $1.77 \mathrm{Mb}$ ) have been suggested to be the underlying cause of seizures occurring in patients with WHS. ${ }^{18-20}$ This patient, with late onset epilepsy (short partial seizures), could have one of the gene copies affected by the breakpoint.

\section{Case 4}

Case 4 was a 10 year old boy with moderate MR and mild dysmorphic facial features (short and broad middle face, prominent chin) in combination with a behavioural disturbance with temper tantrums and sleeping disorder. He had postnatal growth retardation but developed overweight from the age of 3. A deletion of approximately $2 \mathrm{Mb}$ involving two clones was detected at $17 \mathrm{pl} 1.2$ (fig lE). The deletion was proximal but close to the Smith-Magenis syndrome repeat gene clusters, SMS-REPs. ${ }^{21}$ We therefore investigated this patient for SMS microdeletion by FISH using an SMS commercially available probe (Qbiogene, Illkirch, France). No deletion was detected using this probe, but the patient's phenotype showed many features overlapping with those of SMS. The expression of the genes responsible for the SMS phenotype might be influenced by a heterochromatin induced position effect in this patient. Nevertheless, thorough genotype-phenotype correlation of this case together with other SMS patients would be needed to determine if the critical region for SMS needs to be adjusted.

\section{DISCUSSION}

Array-CGH has proven to be an important tool to detect submicroscopic chromosomal aberrations. Two previous array-CGH screenings performed on mentally retarded patients have reported detection rates as high as $15 \%$ and $24 \%$, respectively. ${ }^{78}$ However, almost half of the aberrations detected were single clone gains or losses. These small imbalances are more difficult to distinguish from normal variants, especially if these small imbalances are inherited from one of the parents. Despite the fact that inherited imbalances could account for the abnormal phenotype in affected children through an epigenetic or unrecognised mechanism in rare cases of recessive disorders, it is however more likely that single clone imbalances inherited from phenotypically normal parents are not the cause of the phenotype in their affected offspring. After exclusion of the abnormalities that were inherited or were listed in the Database of Genomic Variants, the detection rate is closer to $10 \%$ in both previously reported array-CGH screening studies.

We detected chromosome imbalances in $9.8 \%$ of the investigated cases. The aberrations involved 2-14 clones and none of the aberrations were inherited. Two of the aberrations detected were estimated to be $\geqslant 10 \mathrm{Mb}$ in size, but still they were not previously detected by standard karyotyping. Furthermore, other genome-wide screening studies have reported large aberrations that escaped detection by G-banding analysis. This illustrates that more accurate and reliable methods are needed to exclude chromosome imbalances in mentally retarded patients. Moreover, high resolution screening using array-CGH not only detects submicroscopic chromosomal imbalances, but also allows accurate delineation of the duplicated or deleted chromosomal segments. This is crucial for genotype-phenotype correlations and for identifying candidate genes involved in the development of mental disability and dysmorphism.

When subtelomeric screening was widely performed, numerous subtelomeric rearrangements were mapped, phenotype-genotype correlations were performed, ${ }^{22}$ and polymorphisms were identified. ${ }^{23}{ }^{24}$ Array-CGH offers the same possibilities, but now including the whole genome. The online databases to access phenotypes correlated to gene dose alterations, such as DECIPHER (http://www.sanger.ac.uk/ PostGenomics/decipher/) and ECARUCA (http://www.ecaruca. net/), will become tremendously helpful for interpreting the results of these analyses. Array-CGH has already been used successfully for delineation of known microdeletion/microduplication syndromes, ${ }^{21}{ }^{25-28}$ and recently the CHD7 gene causing CHARGE syndrome was identified by array-CGH screening of patients diagnosed with this syndrome. ${ }^{29}$

In addition to chromosome imbalances, we detected a large number of single clone gains and losses that were interpreted as normal variants, since they are frequently observed in normal healthy individuals or were observed in several patients with different clinical phenotypes. Therefore, it is unlikely that these polymorphic gains and losses influence the phenotypes of our patients. In a previous study testing the same microarray on 10 patients with well characterised chromosome abnormalities, ${ }^{13}$ we did not detect any polymorphisms, but a number of clones gave false negative results. This is most likely due to the smaller sample size used, but more importantly a more restricted threshold was used for array data analysis. Polymorphisms without clinical significance are present in the population, including regions containing coding genes. Because of the frequent LCVs found in individuals without clinical manifestations, ${ }^{9}{ }^{10}$ the clinical interpretation of array-CGH is complicated.

Shaw-Smith et al speculated that array-CGH possibly could give a detection yield as high as $20 \%$ when screening patients with MR, dysmorphism, normal karyotypes by G-band analysis, and if subtelomeric regions are not excluded prior to array-CGH analysis. ${ }^{7}$ Subtelomeric rearrangements are currently reported to occur in $5 \%$ of investigated cases. ${ }^{2}$ The two previously reported array-CGH studies ${ }^{78}$ and this current study detected abnormalities of clinical significance in approximately $10 \%$ in a comparable group of patients. The detection rate speculated by Shaw-Smith et al might thus be slightly overestimated. Interestingly, previously reported studies using HR-CGH with a resolution of 2-3 Mb, also reported approximately $10 \%^{4}$ and $12 \%^{30}$ detection rates, respectively. These findings could imply that array-CGH with an average resolution of $1 \mathrm{Mb}$ does not dramatically increase the detection of pathogenic chromosome imbalances compared to HR-CGH performed on metaphases. However, a considerable number of aberrations detected by array-CGH were less than $3 \mathrm{Mb}$ in size and would most likely have escaped detection by HR-CGH. Furthermore, array-CGH allows for rapid and more precise mapping of candidate genes giving rise to certain phenotypes. It will become even more useful for screening mentally retarded patients for constitutional chromosome imbalances when a tiling resolution array consisting 32500 overlapping BAC clones becomes readily available. ${ }^{31}$ This array will detect most of the submicroscopic aberrations that remain undetected by the methods discussed above and will give us more insight into the diversity of the human genome by detecting polymorphisms. Structural polymorphisms may play an analogous role in determining genetic diversity within the human population and there might be relationships between large scale copy number variations and susceptibility to genetic rearrangements and development of disorders. It is well recognised 
that segmental duplications in the human genome are located within regions which contain recurring de novo rearrangements causing several developmental disorders, such as Prader Willi/Angelman syndromes, DiGeorge syndrome, Charcot Marie Tooth syndrome, Smith Magenis syndrome, and Williams-Beuren syndrome. ${ }^{32}$ Regions on chromosome $8 \mathrm{p}$ and $4 \mathrm{p}$ are prone to genetic rearrangements, due to large olfactory receptor-gene (OR) clusters causing unequal crossovers between two OR clusters in these regions. ${ }^{33}$ Duplications on the short arm of chromosome $8 \mathrm{p}$ have frequently been reported with or without clinical manifestations and deletion on the short arm of chromosome $4 \mathrm{p}$ causes WHS. Publicly accessible databases containing normal variants are very useful tools for determining polymorphisms, as results from different investigators world-wide can be accessed. In this way we will gain more understanding of the human variations in the genome to help discover its possible function.

In conclusion, high resolution screening of patients with idiopathic MR by array-CGH has the potential to become an important tool in the clinical diagnostic setting. Thorough phenotype-genotype correlation will be needed for the determination of the clinical significance of genomic imbalances. The characterisation of polymorphisms will provide more insight into the plasticity of the human genome.

\section{ACKNOWLEDGEMENTS}

We are grateful to the patients and their parents. We want to thank Dr Kerstin Sars Zimmer for referring patients and Dr Elisabeth Blennow for critical review. We also want to thank the Wellcome Trust Sanger Institute and BACPAC Resource Center, Children's Hospital Oakland Research Institute for providing BAC and PAC clones.

\section{ELECTRONIC-DATABASE INFORMATION}

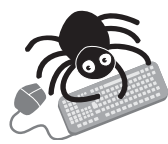

The following organisations and websites are referred to in the text: BACPAC Resources Center, http:// www.chori.org/bacpac/; Welcome Trust Sanger Institute, http://www.sanger.ac.uk/cgi-bin/teams/ team38/CloneRequest/CloneRequest; Resources for Molecular Cyłogenetic, University of Bari, http:// www.biologia.uniba.it/rmc; Spectral Genomics SpectralWare software, http://service.spectralgenomics.com/; Database of Genomic Variants, http:// projects.tcag.ca/variation; ECARUCA, http:// www.ecaruca.net/; DECIPHER, http://www.sanger. ac.uk/PostGenomics/decipher/.

\section{Authors' affiliations \\ J Schoumans, C Ruivenkamp, B-M Anderlid, M Nordenskjöld,} Department of Molecular Medicine, Karolinska Hospital, CMM L8:02, SE-17176 Stockholm, Sweden

E Holmberg, Department of Clinical Genetics, Sahlgrenska University Hospital/East, S-41685 Gothenburg, Sweden

M Kyllerman, The Queen Silvia Children's Hospital, Section of Neuropediatrics, Gothenburg University, Gothenburg, Sweden

This work was supported by funds from the Swedish Medical Research Council, Frimurarna Barnahuset Foundation, Linnea och Josef Carlsson Stiftelse, Stiftelsen Sävstaholm, and the Ronald McDonald Child Foundation.

Competing interests: none declared

Correspondence to: Jacqueline Schoumans, Department of Molecular Medicine, Karolinska Hospital, CMM L8:02, SE-17176 Stockholm,

Sweden; Jacqueline.schoumans@cmm.ki.se

Revised version received 30 December 2004

Accepted for publication 17 January 2005

\section{REFERENCES}

1 Biesecker LG. The end of the beginning of chromosome ends. Am J Med Genet 2002;107(4):263-6.

2 Flint J, Knight S. The use of telomere probes to investigate submicroscopic rearrangements associated with mental retardation. Curr Opin Genet Dev 2003;13(3):310-6.

3 Kirchhoff M, Rose H, Maahr J, Gerdes T, Bugge M, Tommerup N, Tumer Z, Lespinasse J, Jensen PK, Wirth J, Lundsteen C. High resolution comparative genomic hybridisation analysis reveals imbalances in dyschromosomal patients with normal or apparently balanced conventional karyotypes. Eur J Hum Genet 2000;8(9):661-8

4 Ness GO, Lybaek H, Houge G. Usefulness of high-resolution comparative genomic hybridization (CGH) for detecting and characterizing constitutional chromosome abnormalities. Am J Med Genet 2002:113(2):125-36.

5 Schoumans J, Nielsen K, Jeppesen I, Anderlid BM, Blennow E, BrondumNielsen K, Nordenskjold M. A comparison of different metaphase CGH methods for the detection of cryptic chromosome aberrations of defined size. Eur J Hum Genet 2004; 12(6):447-54

6 Snijders AM, Nowak N, Segraves R, Blackwood S, Brown N, Conroy J, Hamilton G, Hindle AK, Huey B, Kimura K, Law S, Myambo K, Palmer J, Ylstra B, Yue JP, Gray JW, Jain AN, Pinkel D, Albertson DG. Assembly of microarrays for genome-wide measurement of DNA copy number. Nat Genet 2001;29(3):263-4.

7 Shaw-Smith C, Redon R, Rickman L, Rio M, Willatt L, Fiegler $\mathrm{H}$, Firth $\mathrm{H}$, Sanlaville D, Winter R, Colleaux L, Bobrow M, Carter NP. Microarray based comparative genomic hybridisation (array-CGH) detects submicroscopic chromosomal deletions and duplications in patients with learning disability/ mental retardation and dysmorphic features. J Med Genet 2004;41(4):241-8.

8 Vissers LE, de Vries BB, Osoegawa K, Janssen IM, Feuth T, Choy CO, Straatman $H$, van der Vliet W, Huys EH, van Rijk A, Smeets D, van Ravenswaaij-Arts CM, Knoers NV, van der Burgt I, de Jong PJ, Brunner HG, van Kessel AG, Schoenmakers EF, Veltman JA. Array-based comparative genomic hybridization for the genomewide detection of submicroscopic chromosomal abnormalities. Am J Hum Genet 2003;73(6):1261-70.

9 Sebat J, Lakshmi B, Troge J, Alexander J, Young J, Lundin P, Maner S, Massa H, Walker M, Chi M, Navin N, Lucito R, Healy J, Hicks J, Ye K, Reiner A, Gilliam TC, Trask B, Patterson N, Zetterberg A, Wigler M. Largescale copy number polymorphism in the human genome. Science 2004;305(5683):525-8

10 lafrate AJ, Feuk L, Rivera MN, Listewnik ML, Donahoe PK, Qi Y, Scherer SW, Lee C. Detection of large-scale variation in the human genome. Nat Genet 2004;36(9):949-51.

11 de Vries BB, White SM, Knight SJ, Regan R, Homfray T, Young ID, Super M, McKeown C, Splitt M, Quarrell OW, Trainer AH, Niermeijer MF, Malcolm S, Flint J, Hurst JA, Winter RM. Clinical studies on submicroscopic subtelomeric rearrangements: a checklist. J Med Genet 2001 38(3):145-50.

12 Anderlid BM, Schoumans J, Anneren G, Sahlen S, Kyllerman M, Vujic M, Hagberg B, Blennow E, Nordenskjold M. Subtelomeric rearrangements detected in patients with idiopathic mental retardation. Am J Med Genet 2002; 107(4):275-84.

13 Schoumans J, Anderlid BM, Blennow E, Teh BT, Nordenskjold M. The performance of $\mathrm{CGH}$ array for the detection of cryptic constitutional chromosome imbalances. J Med Genet 2004;41(3):198-202.

14 Nixon J, Oldridge M, Wilkie AO, Smith K. Interstitial deletion of $2 q$ associated with craniosynostosis, ocular coloboma, and limb abnormalities: cytogenetic and molecular investigation. Am J Med Genet 1997;70(3):324-7.

15 Boles RG, Pober BR, Gibson LH, Willis CR, McGrath J, Roberts DJ, Yang Feng TL. Deletion of chromosome 2q24-q31 causes characteristic digital anomalies: case report and review. Am J Med Genet 1995;55(2):155-60.

16 Koolen DA, Vissers LE, Nillesen W, Smeets D, van Ravenswaaii CM Sistermans EA, Veltman JA, de Vries BD. A novel microdeletion, del(2)(q22.3q23.3) in a mentally retarded patient, detected by array-based comparative genomic hybridization. Clin Genet 2004;65(5):429-32.

17 Mowat DR, Wilson MJ, Goossens M. Mowat-Wilson syndrome. J Med Genet 2003;40(5):305-10.

18 Zollino M, Lecce R, Fischetto R, Murdolo M, Faravelli F, Selicorni A, Butte C, Memo L, Capovilla G, Neri G. Mapping the Wolf-Hirschhorn syndrome phenotype outside the currently accepted WHS critical region and defining a new critical region, WHSCR-2. Am J Hum Genet 2003;72(3):590-7.

19 Van Buggenhout G, Melotte C, Dutta B, Froyen G, Van Hummelen P, Marynen P, Matthijs G, de Ravel T, Devriendt K, Fryns JP, Vermeesch JR. Mild Wolf-Hirschhorn syndrome: micro-array $\mathrm{CGH}$ analysis of atypical $4 \mathrm{p} 16.3$ deletions enables refinement of the genotype-phenotype map. J Med Genet 2004;41(9):691-8

20 Rauch A, Schellmoser S, Kraus C, Dorr HG, Trautmann U, Altherr MR, Pfeiffer RA, Reis A. First known microdeletion within the Wolf-Hirschhorn syndrome critical region refines genotype-phenotype correlation. Am J Med Genet 2001;99(4):338-42.

21 Shaw CJ, Shaw CA, Yu W, Stankiewicz P, White LD, Beaudet AL, Lupski JR. Comparative genomic hybridisation using a proximal 17p BAC/PAC array detects rearrangements responsible for four genomic disorders. J Med Genet 2004:41(2):113-9.

22 de Vries BB, Winter R, Schinzel A, van Ravenswaaij-Arts C. Telomeres: a diagnosis at the end of the chromosomes. J Med Genet 2003;40(6):385-98.

23 Joyce CA, Dennis NR, Cooper S, Browne CE. Subtelomeric rearrangements: results from a study of selected and unselected probands with idiopathic mental retardation and control individuals by using high-resolution G-banding and FISH. Hum Genet 2001;109(4):440-51

24 van Karnebeek CD, Koevoets C, Sluijter S, Bijlsma EK, Smeets DF, Redeker EJ, Hennekam RC, Hoovers JM. Prospective screening for subtelomeric 
rearrangements in children with mental retardation of unknown aetiology: the Amsterdam experience. J Med Genet 2002;39(8):546-53

25 Yu W, Ballif BC, Kashork CD, Heilstedt HA, Howard LA, Cai WW, White LD, Liu W, Beaudet AL, Bejiani BA, Shaw CA, Shaffer LG. Development of a comparative genomic hybridization microarray and demonstration of its utility with 25 well-characterized 1 p36 deletions. Hum Mol Genet 2003; 12(17):2145-52.

26 Wang NJ, Liu D, Parokonny AS, Schanen NC. High-resolution molecular characterization of $15 q 11-q 13$ rearrangements by array comparative genomic hybridization (array CGH) with detection of gene dosage. Am J Hum Genet 2004;75(2):267-81.

27 Veltman JA, Jonkers Y, Nuijten I, Janssen I, van der Vliet W, Huys E, Vermeesch J, Van Buggenhout G, Fryns JP, Admiraal R, Terhal P, Lacombe D, van Kessel AG, Smeets D, Schoenmakers EF, van Ravenswaaii-Arts CM. Definition of a critical region on chromosome 18 for congenital aural atresia by arrayCGH. Am J Hum Genet 2003;72(6):1578-84.

28 Mantripragada KK, Tapia-Paez I, Blennow E, Nilsson P, Wedell A, Dumanski JP. DNA copy-number analysis of the 22q11 deletion-syndrome region using array-CGH with genomic and PCR-based targets. Int J Mol Med 2004;13(2):273-9.
29 Vissers LE, van Ravenswaaii CM, Admiraal $R$, Hurst JA, de Vries BB, Janssen IM, van der Vliet WA, Huys EH, de Jong PJ, Hamel BC, Schoenmakers EF, Brunner HG, Veltman JA, van Kessel AG. Mutations in a new member of the chromodomain gene family cause CHARGE syndrome. Nat Genet 2004:36(9):955-7.

30 Kirchhoff M, Pedersen S, Kjeldsen E, Rose H, Dunø M, Kølvraa S, Lundsteen C. Prospective study comparing HR-CGH and subtelomeric FISH for investigation of individuals with mental retardation and dysmorphic features and an update of a study using only HR-CGH. Am J Med Genet 2004;127A(2):111-7.

31 Ishkanian AS, Malloff CA, Watson SK, DeLeeuw RJ, Chi B, Coe BP, Snijders A, Albertson DG, Pinkel D, Marra MA, Ling V, MacAulay C, Lam WL. A tiling resolution DNA microarray with complete coverage of the human genome. Nat Genet 2004;36(3):299-303.

32 Emanuel BS, Shaikh TH. Segmental duplications: an 'expanding' role in genomic instability and disease. Nat Rev Genet 2001 ;2(10):791-800.

33 Giglio S, Broman KW, Matsumoto N, Calvari V, Gimelli G, Neumann T, Ohashi H, Voullaire L, Larizza D, Giorda R, Weber JL, Ledbetter DH, Zuffardi $O$. Olfactory receptor-gene clusters, genomic-inversion polymorphisms, and common chromosome rearrangements. Am J Hum Genet $2001 ; 68(4): 874-83$.

\section{Get published within days of acceptance with JMG}

We are delighted to announce that the Journal of Medical Genetics launched a "publish ahead of print" programme in March 2005. Selected papers are fast tracked and published online months before they appear in the print journal.

Papers of more significance to the international ophthalmology community are published within days of acceptance. The first published article is the raw accepted manuscript; edited and typeset versions are also published as soon as they are available.

In addition to being available on JMG Online, the publish ahead of print articles are searchable through PubMed/Medline - establishing primacy for your work. They are linked from the JMG Online home page.

The $J M G^{\prime}$ 's publish ahead of print programme is unique among the major clinical genetics journals - to take advantage of this service submit your papers to Journal of Medical Genetics using our online submission and review system Bench>Press (http://submit-jmg.bmijournals. com). For further information contact JMG@bmigroup.com. 